\title{
DIREITOS DA CRIANÇA E DO ADOLESCENTE: UM DEBATE NECESSÁRIO ${ }^{I}$
}

\author{
Esther Maria de Magalhães Arantes*
}

\section{Resumo}

Para dar força de lei aos direitos da criança, a Organização das Nações Unidas constituiu, em 1979, um Grupo de Trabalho que deu início à elaboração do texto da Convenção sobre os Direitos da Criança, debatido durante 10 anos. Adotada por unanimidade, a Convenção é considerada um dos mais importantes instrumentos de direitos humanos jamais adotado pela comunidade internacional. No entanto, e sem que isto implique desconsiderar a sua importância, a Convenção deve ser problematizada, levando-se em conta os dez anos em que o pré-texto foi debatido, a complexidade de suas afirmaçóes e as dificuldades existentes para sua efetivação.

Palavras-chave: convenção sobre os direitos da criança; contexto histórico; mudanças; desafios.

\begin{abstract}
ChILdREN AND ADOLESCENTS' RIGHTS: A NECESSARY DEBATE

To give force of law on child rights, the United Nation established in 1979 a Working Group to begin drafting the text of the Convention on the Rights of the Child, which was debated for 10 years. Adopted unanimously, the Convention is considered one of the most important buman rights instruments ever adopted by international community. However, without this implying to disregard their importance, the Convention should be analyzed taking into account the ten years that the pre-text was discussed, the complexity of their claims and the difficulties in its implementation.
\end{abstract}

Keywords: convention on the rights of the child; historical context; changes; challenges.

* Programa de Pós-graduação em Políticas Públicas e Formação Humana, UERJ e Departamento de Psicologia, PUC-Rio, Rio de Janeiro, RJ, Brasil. E-mail: arantes@puc-rio.br. 


\section{Introdução}

O tema dos direitos humanos de crianças e adolescentes, particularmente os direitos afetivo-sexuais, tem se mostrado bastante complexo e, em respeito a esta complexidade, permitam-me, ainda que de maneira breve, pensá-lo a partir do contexto mais geral da Convenção sobre os Direitos da Criança (CDC), por duas razóes: primeiro, pelo pouco debate no Brasil sobre a Convenção e, segundo, porque algumas propostas e projetos destinados a crianças e adolescentes brasileiros têm origem em programas internacionais, nem sempre acompanhados de uma discussão prévia que os recomende.

Embora possamos datar a preocupação internacional com os direitos da criança como tendo início no final do século XIX, apenas no século XX foram aprovadas a Declaraçáo de Genebra (1924 e 1948) e a Declaraçáo sobre os Direitos da Criança (1959), afirmando tais direitos como sendo os de proteção e sobrevivência, a partir da consideração de que, em razáo de sua idade e imaturidade, a criança necessita de proteção e cuidados especiais.

Por iniciativa da delegaçáo da Polônia, em 1978, e para dar força de lei aos direitos da criança, a ONU constituiu, em 1979, um Grupo de Trabalho (Working Group on the Question of a Convention on the Rights of the Child) para dar início à elaboração do pré-texto da Convenção, que foi debatido durante 10 anos. Adotada por unanimidade pela Assembleia Geral, em 20 de novembro de 1989, a Convenção sobre os Direitos da Criança foi aberta para ratificação em 26 de janeiro de 1990 e entrou em vigor em 2 de setembro do mesmo ano, significando que cada Estado Parte da CDC assumia o compromisso de construir uma ordem legal interna voltada para a sua efetivação. O Brasil ratificou a CDC em 20 de setembro de $1990^{2}$.

Contendo um preâmbulo e uma parte substantiva, onde são apresentados os direitos da criança, e duas outras partes, dedicadas ao seu cumprimento e monitoramento, a Convenção é considerada um dos documentos mais importantes de direitos humanos aprovado pela comunidade internacional, afirmando quatro grandes princípios ético-filosóficos e jurídicos em relação aos quais deve-se ler toda a Convenção. Sáo eles: 1) não discriminação; 2) melhor interesse da criança; 3) direito à sobrevivência e ao desenvolvimento e 4) respeito à opiniáo da criança.

Embora a Convenção tenha sido até o momento ratificada por 193 países, 64 fizeram reservas e declaraçôes interpretativas aos seus artigos para compatibilizá-la com a cultura, a religião e a legislação do país. Muitos foram os assuntos que geraram discordâncias e debates, como, por exemplo, o estabelecimento de 
uma idade mínima e máxima para a própria definição de criança, implicando em discutir se a sua proteção deveria incluir a proibição do aborto e, também, a proibição da participação em conflitos armados, que a CDC fixou em 15 anos, apesar da forte oposição de diversos países.

Outros temas discutidos foram, por exemplo: se a criança deve ou não ter liberdade de escolha religiosa; se o princípio da não-discriminação implica na obrigação dos países de garantirem os mesmos direitos às crianças nacionais $\mathrm{e}$ estrangeiras e, também, às que entraram ilegalmente no país e se uma criança adotada ou concebida através de inseminação artificial tem o direito às informaçóes sobre os seus pais biológicos.

Apenas para dar uma ideia do que tais discussóes implicam, cito uma decisão do Supremo Tribunal do Estado de Maryland, nos EUA, que reconheceu o direito de anulação da paternidade já reconhecida, caso o teste de DNA comprove ser negativo em relação à paternidade suposta. Ante o argumento de que tal decisão contraria o princípio do interesse superior da criança, a Corte opinou que este interesse não pode prevalecer sobre a verdade (Pilotti, 2001, p. 55).

Outro questionamento feito à Convenção diz respeito à participação majoritária de países europeus, além dos Estados Unidos da América e Canadá, na elaboração do Grupo de trabalho encarregado de sua elaboração.

Segundo vários estudiosos como Pilotti (2001), somente os países industrializados do ocidente formaram um bloco claramente identificável, denominado "grupo ocidental". No contexto inicial dos debates sobre a CDC, que era o contexto da Guerra Fria, os direitos humanos faziam parte da confrontação política entre os países do Leste e Oeste, sendo que a disputa entre os blocos se dava também na primazia concedida aos diferentes tipos de direitos. Os países pertencentes ao bloco soviético enfatizavam os direitos econômicos e sociais, enquanto países ocidentais, particularmente os EUA, tendiam a reconhecer como direitos humanos apenas os de caráter civil e político.

Esta tensão pode ser mais bem visualizada levando-se em conta o fato de que, apesar de 26 países da Europa, 19 da Ásia, 10 do Oriente Médio, 7 das Américas e 2 do Caribe terem feito reservas e declaraçóes interpretativas aos artigos da CDC, apenas 2 países da Europa receberam Objeções, sendo todos os demais não-europeus (Grahn-Farley, 2002). As objeções foram feitas com base no Art. 51 da Convenção:

1. O Secretário-Geral das Naçōes Unidas receberá e comunicará a todos os Estados Partes o texto das reservas feitas pelos Estados no momento da ratificação ou da adesão; 
2. Não será permitida nenhuma reserva incompatível com o objetivo e o propósito da presente Convenção;

3. Quaisquer reservas poderáo ser retiradas a qualquer momento mediante uma notificaçáo nesse sentido dirigida ao Secretário-Geral das Nações Unidas, que informará a todos os Estados. Essa notificação entrará em vigor a partir da data de recebimento da mesma pelo Secretário-Geral (UNICEF, 1989, p. 33).

Assim, apesar de o texto final da Convenção ter sido bastante negociado para levar em conta as ponderaçóes dos diferentes países, restaram dificuldades que não devemos desconhecer e que têm impacto diretamente na maneira como lidamos com questôes relativas às crianças indígenas, por exemplo. Certamente a questão da multiculturalidade não é um debate simples e tem colocado em lados opostos aqueles que sustentam que os direitos individuais não são suficientes para dar conta das identidades forjadas nas culturas e todos aqueles que consideram que os direitos coletivos não devem prevalecer sobre os direitos individuais. No entanto, não nos deteremos na discussão desta questão, que foge aos objetivos deste texto.

A Convençáo também tem sido criticada por autores que consideram que os direitos da criança deveriam permanecer sendo apenas os de proteção, posição que contrasta com todos aqueles que denunciam a proteção como uma forma de opressão dos adultos sobre as crianças.

$\mathrm{Na}$ França, após a Convenção ter sido ratificada, um questionamento intenso tomou lugar entre os partidários dos direitos da criança como sendo apenas direitos de proteção. Para esta corrente, não se pode desconstruir a infância como menoridade jurídica, tratando-se apenas de assegurar a ela uma melhor e mais eficaz proteção e não de outorgar-lhe novos direitos. Neste sentido, a menoridade jurídica não confina a criança ao não-direito, apenas permite-lhe não ser submetida aos deveres dos adultos. A crítica de Irène Théry (1992/2007) é que os partidários dos novos direitos da criança não se limitaram a denunciar o sofrimento das crianças que se encontravam em situação de exploração, miséria e opressão, ou seja, não se limitaram a denunciar as falhas da proteção, mas afirmaram que todas as crianças tinham sido, até então, objeto de opressão pela sua condição comum de menoridade jurídica.

Segundo a autora, a menoridade não confina a criança ao não-direito; ela significa que, embora seja titular de direitos desde o nascimento, a criança não poderia ser intimada a exercê-los imediatamente por si mesma e, portanto, indica aquele que tem o poder e o dever de velar pelo respeito a seus direitos fundamentais. Em outras palavras, o que diferencia a infância do estado adulto justifica con- 
ceber para ela direitos peculiares, específicos, derivados de sua necessidade própria de proteção: os direitos dos menores. Nesse sentido, os "direitos da criança” são os de seres humanos particularmente vulneráveis porque ainda não são autônomos. A incapacidade jurídica não é senão o direito à irresponsabilidade, isto é, o direito a náo ser submetido aos deveres que a capacidade implica. É essa acepção protetora que preside a Convenção de Genebra, de 1924, sobre os "direitos da criança”, como também a Declaração dos Direitos da Criança da ONU de 1959 (Théry, 1992/2007).

Para John Holt (1975), educador norte-americano considerado um dos pioneiros na luta pelos novos direitos da criança, a infância moderna constitui uma forma de aprisionamento à qual toda criança tem o direito de escapar. A partir de severa crítica ao modo como crianças e jovens são educados nas famílias e no sistema escolar norte-americano, propóe que qualquer pessoa jovem que assim o desejar deve ter os direitos, privilégios, obrigaçóes e responsabilidades do cidadão adulto, desde que demonstre capacidade e responsabilidade para tal. Isto inclui, dentre outros: 1) o direito a igual tratamento pela lei, significando que, em qualquer situação, não seja tratado pior do que o adulto seria; 2) direito de votar e tomar parte em todos os assuntos relacionados à política; 3) direito de ser responsável pela sua própria vida; 4) direito de trabalhar por dinheiro; 5) direito à privacidade; 6) direito à independência e responsabilidade financeira, que inclui adquirir, comprar, vender propriedade e fazer empréstimos bancários, assinar contratos, etc.; 7) direito a decidir sobre sua própria educação; 8) direito de viajar, de viver longe da casa dos pais, de escolher ou estabelecer-se em sua própria casa; 9) direito de receber a mesma renda mínima garantida pelo Estado ao cidadão adulto; 10) direito de escolher, em base de consenso mútuo, um guardião ou responsável que não seus pais biológicos; 11) direito de fazer, em geral, o que qualquer adulto faz legalmente (Holt, 1975).

No Brasil, em importante trabalho de pesquisa, Pinheiro (2006) mostrou como diferentes representaçóes de criança estiveram presentes nos debates da Constituinte. Ao lado da representação como sujeito de direitos, também estiveram presentes as representaçóes da criança como objeto da assistência, controle, disciplinamento e repressão. $\mathrm{O}$ fato de ter-se afirmado, através do Art. 227 da Constituição Federal de 1988, que crianças e adolescentes são titulares de direitos não significou que as demais representaçóes tenham sido automaticamente banidas da vida social. Ao contrário, persistem em maior ou menor grau e são passíveis de emergir com grande força, dependendo dos agenciamentos que se dão em torno da infância e da adolescência em determinada conjuntura. 
Dentre essas duas tradiçóes, cuja ênfase recai seja na proteção, seja na autonomia, qual a que funda a Convenção sobre os Direitos da Criança? A CDC não afirma nenhuma das duas tradiçóes inteiramente, uma vez que ao lado dos direitos de proteção acrescenta os direitos de liberdade e participação. Para Irène Théry (1992/2007), o fato de que estejam presentes na Convenção estas duas lógicas, que considera antagônicas, constitui uma verdadeira contradição, para a qual a Convenção não aponta nenhuma solução.

Particularmente, reconheço a existência de uma tensão e não de uma contradição entre proteção e autonomia. Tensão, no entanto, que necessita ser mais bem pensada e compreendida, pois coloca para todos nós o desafio de entender o caráter não apenas jurídico, mas ético, político e social dos direitos da criança e do adolescente.

Para enfrentarmos este desafio temos que reconhecer, inicialmente, os impasses e dificuldades nos quais nos encontramos. Ou seja: ao lado de uma legislação considerada avançada por trazer a novidade histórica dos direitos, persiste, de maneira muito forte e arraigada em nossas instituiçóes e nas práticas dos diversos profissionais do campo social, em geral, a compreensão da proteção dos direitos da criança como mero assistencialismo, quando não correção e disciplinamento, particularmente em se tratando de crianças e adolescentes pobres.

Temos que reconhecer, igualmente, que, a despeito dos esforços que vêm sendo feitos para eliminar a fome, a desnutrição e a mortalidade infantil, o Brasil continua sendo um país muito desigual, persistindo situaçóes de extrema pobreza, vulnerabilidade e violência.

Além do mais, a persistência dos pensamentos menorista e higienista, aliados às condiçóes de vulnerabilidade de certos grupos da população, vem gerando, de maneira preocupante, práticas ditas de proteção da criança, supostamente apoiadas no ECA (Estatuto da Criança e do Adolescente) e na CDC, que se assemelham a verdadeiros tribunais de exceção, nos quais mulheres pobres têm sido separadas de seus filhos ou afastadas de seus bebês, alguns deles ainda na maternidade. Basta lembrarmos o caso, ocorrido em 15 de março de 2010, da menina de 1 ano e 2 meses tirada à força dos braços da mãe cigana com grande violência e levada para um abrigo na cidade de Jundiaí, interior de São Paulo.

Além das tensóes discutidas acima, destacamos outra, envolvendo o direito da criança de se expressar e de ser ouvida. Como já mencionado anteriormente, o direito da criança de participação constitui um dos quatro grandes princípios da CDC, sendo os demais o princípio da não-discriminação, o direito à vida e ao 
desenvolvimento e o princípio do melhor interesse da criança. Assim, a partir da CDC, os direitos da criança não mais se limitam aos direitos que derivam de sua vulnerabilidade (proteção) e dependência do adulto (provisão), sendo o Art. 12 da CDC um dos mais celebrados internacionalmente:

1. Os Estados Partes assegurarão à criança, que for capaz de formar seus próprios pontos de vista, o direito de exprimir suas opinióes livremente sobre todas as matérias atinentes à criança, levando-se devidamente em conta essas opinióes em função da idade e maturidade da criança.

2. Para esse fim, à criança será, em particular, dada a oportunidade de ser ouvida em qualquer procedimento judicial ou administrativo que the diga respeito, diretamente ou através de um representante ou órgão apropriado, em conformidade com as regras processuais do direito nacional (UNICEF, 1989, p. 10).

Tendo em vista, no entanto, dificuldades na compreensão e implementação deste direito, o Comitê da ONU sobre os Direitos da Criança (Committee on the Right of the Child) promoveu, em 2006, um dia de discussão para explorar os significados do Art. 12, suas relaçóes com os outros artigos da CDC e as lacunas, boas práticas e temas prioritários para o enriquecimento do tema. A seguir, apresentamos algumas das consideraçóes do Comitê sobre o tema (ONU, 2009).

O Comitê considera que o Art. 12 da CDC é uma provisão singular dentre os tratados de Direitos Humanos na medida em que dispóe tanto sobre o status social como legal da criança que, se, por um lado, carece de total autonomia como os adultos, por outro lado é sujeito de direitos. Esclarece o Comitê que não se deve presumir que as crianças não tenham capacidade de expressar seus pontos de vista, limitando-lhes as oportunidades de participação. Para o Comitê, mesmo a criança de tenra idade pode formar seus pontos de vista, ainda que não verbalmente. Consequentemente, a implementação do Art. 12 requer o reconhecimento e o respeito às formas não-verbais de comunicação, incluindo brincadeiras, linguagem corporal, expressão facial, desenhos e pinturas, nas quais as crianças muito pequenas demonstram compreensão, escolhas e preferências. Em segundo lugar, o Comitê afirma que não é necessário que a criança tenha uma compreensão de todos os aspectos da matéria que a afeta, bastando ter suficiente compreensão para formar, de maneira apropriada, seus pontos de vista. Além do mais, os Estados Parte estão obrigados a desenvolver esforços para permitir que crianças com deficiência e pertencentes às minorias possam expressar seus pontos de vista. 
Se o Comitê reconhece, por um lado, que a criança tem o direito de expressar suas opinióes, por outro lado esclarece que a criança tem o direito de não exercer este direito; que expressar seus pontos de vista é uma escolha e não uma obrigaçáo; e que os Estados Parte devem garantir que a criança receba todas as informaçóes necessárias a uma tomada de decisão em seu melhor interesse.

De acordo com o Art. 12, a criança deve expressar seus pontos de vista "livremente" e não sob pressão ou coação. Ademais, "expressar suas opiniōes livremente" significa expressá-las de seu ponto de vista e não de outros.

Em relaçáo à criança vítima ou testemunha de crimes, o Comitê lembra que todos os processos nos quais a criança participa e é ouvida devem ser transparentes e informativos, devendo a criança ser informada dos procedimentos, propósitos e possíveis consequências de sua participação; voluntário, nunca devendo a criança ser coagida ou obrigada a participar, tendo o direito de parar a qualquer momento; respeitoso, oferecendo à criança a oportunidade de participar; relevante, dando à criança a oportunidade de dizer o que é relevante para ela; amigável, ou seja, adaptado à criança; inclusivo, evitando discriminação; e seguro e sensível a riscos, dentre outros.

Em texto de trabalho do UNICEF - Innocenti Research Centre, Daniel O’Donnell (2009) afirma que o Art. 12 da CDC não postula a necessidade de crianças participarem de procedimentos administrativos e jurídicos, mas apenas confere à criança o direito de expressar seus pontos de vista e serem eles levados em consideração. Assim, expressar seus pontos de vista é um direito e não uma obrigação da criança, significando também que a criança deve expressar seus pontos de vista a partir de suas próprias referências e não das de outros.

De qualquer modo, seja convocando, convidando ou apenas permitindo que crianças testemunhem, o que é relevante, segundo o autor, é que a modalidade da participação da criança deve ser consistente com a totalidade dos direitos e princípios reconhecidos pela CDC bem como por outros documentos internacionais pertinentes.

No levantamento empírico sobre os procedimentos adotados em diferentes países, O’Donnel (2009) encontrou grande variedade, classificando-os, no entanto, em três grandes grupos: 1) Um primeiro grupo de países tem como regra que crianças abaixo de determinada idade não devem ser ouvidas em procedimentos judiciais; 2) Um segundo grupo de países não estipula, via legislação, uma idade mínima para que crianças sejam ouvidas. No entanto, em geral, existe uma idade mínima baseada em jurisprudência ou regulamentação. Esta idade mínima pode ser 6 ou 14 anos, dependendo do país; 3) Um terceiro grupo de países estipula que crianças acima de uma determinada idade devem ser ouvidas. Em procedi- 
mentos de proteção, a idade mínima encontrada variou de 6 a 15 anos, dependendo do país.

Assim, é importante deixar claro que não existe um modelo único a ser adotado e que estaríamos obrigados a cumprir.

No Brasil, fundamentando-se no direito da criança de se expressar e de ser ouvida, encontra-se em andamento proposta de reformulação do Código de Processo Penal, regulamentando a inquirição judicial de crianças. Por outro lado, tanto o Conselho Federal de Psicologia quanto o Conselho Federal de Serviço Social publicaram Resoluçóes diferenciando escuta de inquirição, vedando ao psicólogo e ao assistente social o papel de inquiridor. De acordo com a Resolução do CFP no 010/2010:

A escuta deve ter como princípio a intersetorialidade e a interdisciplinaridade, respeitando a autonomia da atuação do psicólogo, sem confundir o diálogo entre as disciplinas com a submissão de demandas produzidas nos diferentes campos de trabalho e do conhecimento. Diferencia-se, portanto, da inquirição judicial, do diálogo informal, da investigação policial, entre outros (CFP, 2010).

Não se trata, obviamente, segundo Wanderlino Nogueira $\mathrm{Neto}^{3}$, de impor ou de impedir, via legislação, que qualquer pessoa menor de 18 anos, em qualquer situação, seja inquirida em juízo. Trata-se, no entanto, de situar o debate nos marcos dos Direitos Humanos. Neste sentido, segundo o autor, é necessário:

Primeiro: (A) evitar que as crianças sejam usadas como meio de prova único, exclusivo e preponderante em processos penais. Deve-se lutar pelo aperfeiçoamento da investigação processual policial e judicial. (B) lutar para que crianças e adolescentes não tenham sua condiçáo peculiar de desenvolvimento, sua essencialidade/dignidade, sua liberdade, sua diversidade identitária (por exemplo) desrespeitadas nessas situaçóes extraordinárias de depoimento em juízo; isso é o que a ONU chama, em seus documentos sobre DDHH da infância, de "humanização da Justiça" ou dos processos judiciais. Por fim, (C) lutar para que o depoimento judicial não seja confundido com a escuta profissional nas áreas da medicina, psicologia, antropologia, serviço social etc. e que os profissionais que fazem escuta técnica não sejam usados em situaçóes de depoimentos judiciais [...].

Quando, excepcionalmente, se precisar ouvir/inquirir crianças e adolescentes em Juízo (ou quando eles claramente declararem seu desejo de serem ouvidos), é necessário que estejam previamente orientados, empoderados/ potencializados, fortalecidos por uma equipe de advogados, assistentes sociais, psicólogos, antropólogos (crianças indígenas, quilombolas, ciganas, 
povos tradicionais etc.). Mas tudo isso em reserva, sem nenhuma assistência pelas autoridades do sistema de Justiça. E também penso ser importante que essa mesma equipe multiprofissional citada depois do depoimento judicial acompanhe/escute a criança-adolescente a partir de suas expertises e à luz da sua Deontologia profissional (Nogueira Neto ${ }^{4}$ ).

Gostaria, para finalizar, de lembrar que importantes autores nacionais e internacionais (Buckingham, 2000/2007) têm constatado que os debates em torno da infância têm se revestido de crescente ansiedade e pânico moral, além de muita ambiguidade. Isto porque, se, por um lado, as crianças estão sendo percebidas, cada vez mais, como vítimas, como estando em risco, por outro lado há também uma vasta literatura que relaciona tais situaçóes de risco na infância à criminalidade futura.

Assim, filhos de adolescentes, filhos de pais solteiros, moradores de bairros pobres, crianças com pouco rendimento escolar, com baixa inteligência, que conhecem pessoas que usam drogas ou que estão presas, que estudam em escolas de determinados bairros, que foram vítimas de abuso sexual ou do chamado bullying, crianças hiperativas etc. têm sido considerados prováveis criminosos no futuro, ensejando programas e intervençóes diversas.

A filha do psicanalista Jacques Lacan, Judith Miller, que esteve no Brasil em junho de 2011, afirmou, em entrevista a jornalistas, que apresentaria um documentário que a chocou profundamente. $\mathrm{O}$ documentário mostra como crianças são submetidas, na França, a um jogo truncado, no qual não há chance de ganhar. Trata-se de um "teste" para ver como crianças reagem diante do fracasso, em nome do combate à delinquência.

Constatamos, como tendência no Brasil de hoje, uma intensa produção de leis como resposta imediata aos problemas sociais, principalmente quando o fato é exaustivamente mostrado na mídia. Uma nota na coluna do Ancelmo Gois (2011) esclarece que, em 2001, praticamente nenhum jornal de grande circulação nacional mencionou a palavra bullying. Em 2011, só até o mês de abril, o jornal O Globo já tinha mencionado a palavra 100 vezes, o mesmo se dando com a Folha de SP e o Estadão. Esta visibilidade midiática se intensificou em função do massacre ocorrido na escola de Realengo, e inúmeras leis foram propostas para combater o bullying. No entanto, não devemos esquecer que, se uma criança é dita vítima de bullying na escola, provavelmente outra criança será nomeada como autora do bullying, ou seja, como agressora.

Assim, apesar de constantemente mencionarmos que as crianças agora são sujeitos de direitos, parece que nos encontramos numa espécie de armadilha, como se os direitos que as libertam fossem os mesmos que as aprisionam. $\mathrm{Ou}$ 
seja, por um lado dizemos que as crianças têm direito à educação, à vida, à saúde. Por outro, observamos uma medicalização generalizada das crianças em nome de sua adaptação escolar e familiar, para conter sua agressividade e hiperatividade ou para, simplesmente, prevenir supostos e hipotéticos riscos de se tornarem delinquentes, inseguras, mal-sucedidas ou obesas.

Por um lado dizemos que as crianças têm direito à convivência familiar e comunitária e, por outro, dizemos que o lugar mais perigoso para a criança é a sua família e que é importante empoderarmos as crianças, ensinar-lhes os direitos para que elas possam denunciar os seus pais.

Assim, apesar da retórica dos direitos, penso que nos encontramos em momento de grandes dificuldades e retrocessos, no qual constatamos um constante e intenso ataque à agenda dos Direitos Humanos.

Os direitos sexuais e reprodutivos de crianças e adolescentes não poderiam escapar deste movimento. Ou seja, só tem sido permitido serem pensados no modelo da vítima-agressor. E creio que é por isto que estamos aqui hoje, reunidos, para pensarmos tais direitos de outro modo.

\section{Referências}

Buckingam, D. (2000). Crescer na era das mídias eletrônicas. São Paulo: Edições Loyola, 2007. CFP (2010). Resolução do CFP no 010/2010. Brasília: Conselho Federal de Psicologia Grahn-Farley, M. (2002). Crossing Borders - International Child Rights at Home \& Abroad: a symposium on the UN Convention on the Rights of the Child. Capital University Law Review, 30, 657-664. Disponível em <https://culsnet.law.capital.edu/ LawReview/BackIssues/30-4/Grahn-Farley.pdf>. Recuperado em 14 de dezembro de 2010.

Grahn-Farley, M. (2008). Neutral law and Eurocentric lawmaking: a postcolonial analysis of the U.N. Convention on the Rights of the Child. Brooklyn Journal of International Law, 34(1), 1-32. Disponível em <http://papers.ssrn.com/sol3/papers.cfm?abstract_ id=1349146>. Recuperado em 4 de fevereiro de 2011.

Gois, A. (2011). Coluna do Ancelmo. Rio de Janeiro: Jornal O Globo. Em 24/04/2011.

Holt, J. (1975). Escape from childhood. The needs and rights of children. New York: Ballantine Books.

O'Donnel, D. (2009). The right of the children to be heard: chidren's right to have their views taken into account and to participate in legal and administrative proceedings. Innocenti Working Paper, 2009-04, 1-62. Disponível em <http://www.unicef-irc.org/publications/ pdf/iwp_2009_04.pdf>. Recuperado em 25 de abril de 2011. 
ONU (2009). Convention on the Rights of the Child, Fifty-first session. Genebra: CRC/C/ GC/12, 20 July 2009).

Pilotti, F. (2001). Globalización y Convención sobre los Derechos del Niño: el contexto del texto. CEPAL Série Politicas Sociales, 48, 1-79. Disponível em <www.ucm.es/info/...1/pilotti_contexto-del-texto.pdf>. Recuperado em 25 de novembro de 2010.

Pinheiro, A. (2006). Criança e adolescente no Brasil. Por que o abismo entre a lei e a realidade. Fortaleza: Editora UFC.

Théry, I. (1992). Novos direitos da criança - a poção mágica? In: S. Altoé (org.). A Lei e as leis. Direito e psicanálise. Rio de Janeiro: Revinter, 2007.

UNICEF (1989). Convenção sobre os direitos da criança. Nova Iorque: UNICEF. Disponível em <http://www.unicef.org/brazil/pt/resources_10120.htm>. Recuperado em 15 de março de 2011.

\section{Notas}

${ }^{1}$ Parte da pesquisa de Pós-Doutorado, realizada na UFRJ (2010-2011).

${ }^{2}$ Para ler o texto integral da CDC, acessar: <http://www.onubrasil.org.br/doc_crianca.php>.

${ }^{3}$ Comunicação pessoal por e-mail.

${ }^{4}$ Mesmo caso da nota anterior.

Recebido em 18 de setembro de 2011 Aceito para publicação em 16 de janeiro de 2012 